de:

TRANS $\cdot$ núm. I $9.2 \cdot 2015$

ARTICULOS $\cdot 225-241$
En este trabajo nos concentramos en la combinación inglés-español y examinamos los contenidos jurídicos de las páginas web traducidas al español con objeto de individualizar los rasgos conceptuales, estilísticos y terminológicos que presentan. En especial nos interesa analizar la difusión de nuevos conceptos jurídicos y formas de redacción, así como explorar los límites de la aceptabilidad de las traducciones que, por no respetar el genio de la lengua de llegada, vulneran los límites permitidos por las caracteristicas de hibridación o interferencia consustanciales a toda traducción (Toury, 1995; Monzó 2002, 2005; Borja, 2005). En efecto, los problemas de traducción que se plantean van muy ligados a su posible recepción o interpretación en el ordenamiento jurídico de llegada. Sin embargo, las traducciones denotan mucho más su fidelidad al texto de partida que su deber de información hacia el receptor final. A fin de intentar demostrar esta afirmación presentaremos, en paralelo, algunos ejemplos de las traducciones de documentos digitales al catalán. En un ámbito donde el catalán y el castellano comparten un mismo ordenamiento jurídico, es decir, una misma base conceptual, las diferencias en el plano lingüistico nos permiten analizar si la fidelidad al texto de partida es compatible con el deber de información hacia el destinatario final de la traducción. El objetivo de este trabajo es demostrar que las traducciones de los contenidos jurídicos de las páginas web no toman en consideración el ordenamiento jurídico de la cultura de llegada y que ello puede dar lugar a problemas de interpretación 0 , cuando menos, de comprensión por parte del receptor final.

\title{
El deber de información como criterio de aceptabilidad de las traducciones jurídicas de las páginas web
}

\section{The Duty of Information as Criterion of Acceptability in Legal Translations of Web Pages}

In this article we focus on the English-Spanish combination and we examine the legal content of web pages translated into Spanish so as to pinpoint their conceptual, stylistic and terminological features. We are especially interested in studying the spread of new legal concepts and forms of writing, and in discussing the acceptability of translations that do not respect the genius of the target language and thus go beyond the hybridity or interference that characterises all translation (Toury, 1995; Monzó 2002, 2005; Borja, 2005). Thus, we examine the issue of how translations more oriented to the source text are received or interpreted within the target legal system. In order to illustrate this claim we present, as parallel texts, some examples of translations of digital documents into Catalan. Given that Catalan and Spanish share the same legal system and therefore the same conceptual base; differences of a linguistic nature in the translations provide an opportunity to determine whether fidelity to the source text is compatible with the duty of information to receivers. The aim of this paper is to show that translations of legal content on websites do not take into account the legal framework of the target culture, which in turn could lead to problems of interpretation, or at least comprehension, on the part of the final receiver.

KEY WORDS legal translation, legal language, corpus-based approach, standardization, functional approaches, localization. 


\section{INTRODUCCIÓN}

En los últimos años Internet se ha convertido en un corpus multilingüe de gran utilidad para los traductores. La necesidad que tienen las empresas de «comunicar» en diferentes idiomas ha dado lugar a un volumen importante de documentos digitales multilingües, entre los que se incluye la preceptiva información jurídica impuesta por la legislación nacional. Las páginas web de las empresas contienen clausulado $\mathrm{y}$ disposiciones jurídicas sobre condiciones $\mathrm{y}$ licencias de uso, contratos de servicios, normas de privacidad, documentación corporativa, etc. con sus correspondientes traducciones a los idiomas del público potencial al que se dirigen. Toda esta información pone a disposición del traductor millones de palabras traducidas, con su correspondiente contexto, lo que en el pasado sólo era posible obtener tras muchos años de experiencia profesional.

El interés de este tipo de textos viene determinado asimismo por su medio de publicación, ya que se trata de documentos que se divulgan, suscriben y aceptan a través de Internet y son, por ello, de acceso público y libre para todo el mundo. Es precisamente esta facilidad de acceso de los textos originales, y sus correspondientes traducciones, lo que permite, por una parte, su utilización como textos paralelos para nuevos encargos de traducción y, por otra, su conversión en materia prima de la que se nutren las herramientas de cotejo de los corpus multilingües. La tarea de documentación es ahora más fácil que nunca, sin embargo su impacto no siempre mejora el proceso de traducción. En efecto, la justificación de las decisiones de traducción que se alejan de la «norma googleada», es decir, de la traducción más utilizada, resulta hoy en día más difícil tanto para el traductor avezado como para el novel. En el caso del traductor experto porque si, como bien ha apuntado Pym
(2008:326) (véase también, desde las teorías cognitivas de la traducción, Simeoni r998: I4) en la traducción en general muestra una aprensión natural a correr riesgos, en la traducción jurídica esta característica es donde más se manifiesta al tratarse de un ámbito que se considera supeditado a las limitaciones terminológicas y estilísticas impuestas por el derecho (Didier, I990: 254). $\mathrm{Y}$ en cuanto al traductor novel, ducho en las nuevas tecnologías, porque suele convertir el método estadístico, aplicado por los motores de búsqueda, en el criterio principal de validación de los equivalentes.

Además, una gran parte de los contenidos jurídicos que se encuentran en la red están configurados como condiciones generales de la contratación, es decir, como formatos jurídicos altamente estandarizados, lo que facilita su utilización — mediante un simple corta y pegaen contextos distintos al Derecho tecnológico. En definitiva, la accesibilidad de estas fuentes textuales bilingües puede llegar a determinar la pauta de la traducción jurídica y convertirse en el estándar en la traducción de los contratos del inglés al español. Si, en la línea de lo apuntado por Mayoral (2004: 63), todos los participantes en el acto de traducción influyen en la forma de traducir, en este caso, podemos decir que el cliente es a la vez el creador del texto de partida, el iniciador del encargo de traducción y quien marca el modo de traducir.

\section{DICOTOMÍA O BATALLA ENTRE EL DEBER DE INFORMAR AL DESTINATARIO FINAL Y EL DEBER DE FIDELIDAD AL TEXTO DE PARTIDA}

El traductor jurídico que tiene que traducir entre dos ordenamientos jurídicos donde la excepción es encontrar el equivalente absoluto ( de hecho algunos autores reconocen que sólo 
existe un grado óptimo de equivalencia o near equivalent, véase Šarcevic, I988: 440; 1997: 238) se ve obligado a hacer equilibrios entre una relativa creatividad terminológica (ya sea a través de préstamos, calcos, paráfrasis explicativas o neologismos) y la utilización de equivalentes funcionales que cumplan con el requisito de comunicar el mensaje sin perder la referencia a la cultura de partida. Todo ello en tiempo real, con cada nuevo encargo de traducción y sin caer en las numerosas trampas sobre las que los teóricos de la disciplina se encargan de prevenirles. En efecto, tanto desde el punto de vista de la didáctica como de la investigación se hace hincapié en que la traducción de las instituciones jurídicas debe ser objeto de un análisis comparado para cada caso concreto (véase, por ejemplo, Šarcevic (1997: 242, 244). Incluso se ha llegado a afirmar que la dificultad de este trabajo es la mejor protección de la propia profesión: «it seems justifiable to say that legal translation is in practice as well as in theory is [sic] a secure profession demanding special technical knowledge because of its complexity» (Galdia, 2003: 4). Ahora bien, la práctica ausencia de equivalencia, debida a esta incongruencia conceptual (Gémar, I998: 6; Šarcevic, I985: I27), es un arma de doble filo que puede derivar en la posición extrema del «todo vale» a condición de que el receptor sea debidamente advertido de que la traducción que se le ofrece es a título informativo. Nos encontramos de este modo ante traducciones que vuelven al binomio literalidad-fidelidad, es decir, hacia prácticas claramente orientadas a la cultura de partida. Es cierto que, en la mayoría de los casos, la traducción de los contratos cumple una función meramente informativa. Ahora bien, la cuestión que se plantea es si, en la era global, la frecuencia de uso de una determinada traducción puede ser adoptada como criterio principal para determi- nar que resulta «comprensible en la lengua de llegada». Como siempre, la respuesta dependerá del encargo. Sin embargo, en un ámbito de reciente creación como la traducción de los contenidos jurídicos de las páginas web y, en especial, los contratos del Derecho tecnológico, la necesidad y el uso de un término en la lengua de partida y en la lengua de llegada, a través de su correspondiente traducción, se produce de forma casi simultánea, ya que cuando se redacta el texto de partida en inglés estadounidense, en su mayoría, las empresas ya tienen en preparación su traducción o localización en los otros idiomas. En este sentido se puede comparar con la situación de la traducción en jurisdicciones bilingües o multilingües donde, como ha afirmado Šarcevic (2000: I), «the success of an authenticated translation depends on its interpretation and application in practice», es decir, de su aplicación por los tribunales de Justicia en la jurisdicción de recepción. En la traducción de los contenidos jurídicos de las páginas web, y de los contratos del Derecho tecnológico, el texto de llegada no tiene la consideración de texto auténtico sino que se trata únicamente de un texto susceptible de ser interpretado según el derecho aplicable al texto de llegada. Ahora bien, mientras que, por ejemplo, con la terminología informática la creación o acuñación en inglés de un nuevo término conlleva, casi de forma automática, su traducción e incorporación a los otros idiomas (ejemplos recientes de incorporación al DRAE son blog, chat, SMS, tableta, etc.), en traducción jurídica los textos traducidos pueden ser objeto de recepción en el ordenamiento jurídico de llegada y ello debería tener «its implications for the decision-making process of translators» (Šarcevic, 2000: I). En nuestra opinión, siguiendo la teoría planteada por Šarcevic, las traducciones de los contenidos jurídicos de las páginas web deben tomar en 
consideración el Derecho aplicable en cada caso. Estamos de acuerdo en que el objetivo fundamental de la traducción jurídica es comunicar un mensaje generado en otra cultura jurídica. De ahí que el traductor muchas veces se convierta en un buscador de términos traducidos previamente utilizados en la comunidad de recepción (generalmente, compuesta por juristas) para asegurarse de que efectivamente la traducción seleccionada consigue ese objetivo o propósito comunicativo. Hasta tiempos recientes, los traductores se inspiraban en las bases terminológicas y los corpus proporcionados por los organismos internacionales, los tribunales internacionales de Justicia y las jurisdicciones bilingües (como es el caso del Common law en francés de Canadá) para seleccionar la traducción concreta de un concepto que no existe en la cultura de llegada. Se trataba de un ámbito de trabajo bastante cerrado en el que las traducciones en todo momento denotan su origen como tales (mere translations, de acuerdo con Šarcevic, 2000: I) y por ello no pueden ser confundidas con un corpus creado originalmente en una lengua determinada. Así, la mayor o menor capacidad de una técnica de traducción concreta (técnica se utiliza aquí en el sentido establecido por Hurtado, 200I: 268) para ser aceptada como traducción solía venir marcada principalmente por el prestigio de la fuente de procedencia. En efecto, a pesar de lo que parecen defender algunos autores (Weston, r991: 23), el equivalente funcional en traducción jurídica no siempre resulta la mejor opción, ya que puede resultar engañoso e inapropiado debido a la incongruencia conceptual (Šarcevic, 2000: 7). Por otra parte, el recurso al neologismo también debe realizarse con precaución, ya que existe «le risque qu'il [le néologisme] n'est parfois compris que par celui qui a créé le terme nouveau» (Kieffer, I995: 229). Por ello, los expertos aconsejan acompañar los neologismos con una nota del traductor que permita completar la comunicación del mensaje del concepto de partida en la cultura de recepción (Monjean-Decaudin, 20I2: 387). En otras ocasiones, la técnica utilizada puede ser la expansión léxica o paráfrasis cuando se trata de un término culturalmente marcado desconocido en la cultura de llegada (Šarcevic, 2000: 7). Advertimos, por tanto, que la renovación terminológica, en el ámbito de la traducción jurídica, se produce aplicando el criterio de prudencia que también se aprecia en la siguiente afirmación de De Groot (2008: 6):

If one can assume that some users of the target text already encountered at some point or another these neologisms chosen by others in publications to express the terms in question from the source language legal system, one should seriously consider adopting the choice of earlier translators. One should be aware that choosing one's own neologisms could lead to confusion. Naturally, the likelihood of confusion is dependent on the notoriety of the earlier publication, in which a particular neologism was introduced.

\section{I. La traducción de los contenidos juridicos digitales}

Nuestra hipótesis es que la posición hegemónica en el mercado de las empresas desarrolladoras de productos informáticos, estadounidenses en su mayor parte, se utiliza como plataforma para consolidar prácticas jurídicas, en general (por ejemplo, la inclusión de los programas de ordenador dentro de las obras protegidas por la propiedad intelectual), y contractuales, en particular (licencias, avisos legales, condiciones generales de utilización, por citar algunos ejemplos), además de determinar el estándar en la redacción de los textos jurídicos publicados en Internet, tanto en la lengua fuente como en las diferentes lenguas 
de llegada. En efecto, las grandes empresas del sector informático y tecnológico, con su política de descarga libre de contratos y con los valiosos recursos lingüísticos que elaboran y divulgan, no sólo cumplen con los requisitos de información para sus clientes, sino que se convierten en los nuevos referentes terminológicos en la traducción jurídica en general. De este modo, las decisiones adoptadas, como consecuencia de un particular posicionamiento de mercado, nutren los resultados estadísticos obtenidos a través de los motores de búsqueda y terminan, en definitiva, por consolidar unos modelos de traducción, que se convierten en la «norma googleada». Si bien es cierto que el traductor sigue siendo dueño de sus decisiones de traducción, no es menos cierto que la propagación vírica (entiéndase ésta en el sentido metafórico de la palabra) de equivalentes que se consolidan a una velocidad de vértigo, le puede llevar a descartar una técnica determinada de traducción u otro equivalente por tener un impacto de comunicación menor en el receptor final del encargo, quien es, a su vez, usuario de los motores de búsqueda. En este sentido podemos pensar que el catalán jurídico, debido a su menor presencia en la red, incorpora en sus textos traducidos del inglés un menor número de términos inexistentes en el ordenamiento jurídico español, y logra, por ello, un mayor cumplimiento del deber de información hacia el receptor final del texto de llegada.

La existencia de este corpus multilingüe en la red, así como la rápida popularización de herramientas de alineación de textos bilingües de gran calidad (linguee, 2lingual, etc.), diccionarios bilingües online que también ofrecen corpus alineados (véase, por ejemplo, Reverso diccionario) y otras herramientas de corpus ${ }^{\mathrm{I}}$ (webitext,

\footnotetext{
I Para más recursos de consulta de corpus comparables inglés-español, consultar Vargas, 20I2.
}

glosbe, etc.) contribuyen a empujar al traductor hacia una operación traslaticia que se limita a seleccionar términos y frases que, por haber sido previamente traducidos, se pueden considerar validados. Al fin y al cabo, como hemos visto, la selección de una u otra traducción con frecuencia se justifica en la utilización previa por otros traductores y por la comunidad de recepción. Cuando el traductor comprueba, de este modo, la existencia de un equivalente considera validada la operación de comunicación y, por lo tanto, da por aceptable la traducción.

Además, una gran parte de las traducciones volcadas en Internet han sido generadas dentro de procesos automáticos o semiautomáticos de localización en los que prima el concepto proveniente de la informática engineering of reusability. A través de la localización de los programas de ordenador este concepto se exporta al ámbito de translation reuse por cuanto «translation reuse works as a cost-saving approach because the assumption is that the document corpus of most organizations (or at least that part of it relevant to globalization) grows only incrementally, by adding limited amounts of new linguistic material to larger bodies of existing linguistic material» (Shreve, 2006: 310).

\subsection{Los mecanismos del Derecho en la inter- pretación de los contenidos jurídicos online}

En los últimos tiempos las empresas han podido agilizar la contratación a través del uso masivo de formularios electrónicos que les permite participar en decenas de millones de contratos con una gestión rápida, eficiente y, sobre todo, con un coste muy reducido. En efecto, la contratación electrónica en la actualidad recoge un volumen impresionante de transacciones, que representa, en algunos sectores, una auténtica revolución del canal de negocio (las agencias de viajes online, por citar solo un ejemplo, han 
supuesto la práctica extinción de las agencias tradicionales con atención personal). Este fenómeno ha venido además a acelerar la creación de clausulados uniformes que se utilizan en diferentes situaciones contractuales. Nos referimos a las condiciones generales de la contratación o miscelánea constituidas por cláusulas predispuestas, es decir, cláusulas que son redactadas por una de las partes con objeto de ser incorporadas a una pluralidad de contratos. En palabras de Díez-Picazo (2007: 437), «en la economía moderna, una parte muy importante de lo que en su momento llamamos 'contratación en masa' se desarrolla a través de unas condiciones uniformes, preestablecidas o predispuestas por una empresa o grupo de empresas, que las imponen a sus posibles clientes, al celebrar cada uno de los concretos contratos, sin que exista posibilidad de modificación, ni de discusión». Estas cláusulas que se proponen hoy en día a través de Internet se caracterizan, entre otros rasgos, por tratarse de contenidos jurídicos altamente intercambiables que aparecen en ámbitos contractuales tan diversos como la construcción, el transporte, la distribución, la propiedad intelectual, la compraventa internacional de mercaderías, el comercio electrónico, etc.

En algunas formas contractuales, ${ }^{2}$ la llamada miscelánea puede llegar a representar hasta el $60 \%$ o el $75 \%$ del clausulado total del contrato. Estas cláusulas han sido pensadas y redactadas originalmente en inglés y traducidas o reescritas en español, pero mantienen muchos rasgos conceptuales que denotan su origen en otra cultura jurídica, de ahí que se trate de contenidos jurídicos híbridos, como ya hemos analizado

2 En concreto en el corpus ad hoc que hemos elaborado en el seno del Proyecto de investigación LawioN, conformado por licencias de uso de programas de ordenador. Para más información puede consultarse la herramienta creada en la siguiente dirección: http://lawcalisation.com/. en previos trabajos (véase Bestué 2009; 20I3, I52), que además pueden generar problemas de interpretación.

En la mayoría de los casos los contenidos no se presentan como traducciones manifiestas. El propio sistema identifica el país de origen del usuario para derivarlo hacia una u otra interfaz que se presenta en el idioma del país de residencia del usuario. Se trata de empresas globales que realizan su modelo de negocio casi en exclusiva a través de Internet. En estos casos la influencia de la traducción se detecta porque se introducen términos que, analizados desde la perspectiva del Derecho español, generan un problema de interpretación jurídica.

A título de ejemplo, recogemos un fragmento de las condiciones de servicio de un conocido motor de búsqueda:3 "Podemos suspender o cancelar nuestros Servicios si no cumples con nuestras políticas o condiciones o si consideramos que tu conducta puede ser malintencionada».

A continuación intentaremos realizar una interpretación jurídica ex ante del concepto de «conducta malintencionada» que es el que nos interesa analizar. E1 Derecho civil español no ha desarrollado conceptualmente el término conducta malintencionada; se trata, por tanto, de un término desconocido o inexistente que sin embargo debe ser objeto de interpretación. Como ha dejado en evidencia la reciente sentencia recaída en primera instancia en el conocido como asunto Ryanair, ${ }^{4}$ los términos recogi-

3 El motor de búsqueda de Google, que comenzó en I998, ahora se encarga, aproximadamente, del 80\% de todas las consultas. Este ejemplo aparece recogido en las condiciones de uso extraídas de este enlace http://www.google. com/intl/es/policies/terms/ [última consulta, I6/O4/20I4]

4 Nos referimos a la sentencia dictada por el Juzgado mercantil $\mathrm{n}^{\circ} 5$ de Madrid, $\mathrm{n}^{\circ} \mathrm{II}_{3} / \mathrm{I}_{3}$ de 30 de septiembre, en la que se acude a la normativa española en materia de seguridad aérea, Programa Nacional de Seguridad, para interpretar la expresión «mala conducta» recogida en el clausulado de Ryanair y entendiendo por tal la definición 
dos en las condiciones generales de un servicio son interpretados a la luz de la legislación nacional. Así pues los conceptos que son desconocidos en Derecho español deben ser objeto de interpretación a través de las reglas de la hermenéutica jurídica en materia de contratos. 5 En este sentido, el Derecho español establece que cuando las cláusulas son claras debe primar la interpretación literal de las palabras, pero, en caso contario, como podría ser el que se plantea aquí, se ha de acudir a la intención evidente de los contratantes (art. I28I del Código civil). Las condiciones en cuestión recogen una cláusula de sumisión a las leyes de California ${ }^{6}$ y, aunque no establece la remisión al clausulado redactado en inglés a efectos de interpretación, podemos interpretar que la intención evidente de la empresa, predisponente de las condiciones, es «traducir» el término en inglés misconduct, que es el que encontramos en la versión en inglés del mismo clausulado. Así pues, el término "conducta malintencionada» en este contexto podría ser un calco de la expresión inglesa. Mediante la aplicación de los elementos lógicos y sistemáticos de interpretación, podemos llegar a deducir

del pasajero conflictivo recogida en el artículo Io.I.3 del PNS donde se define aquel como «aquellos pasajeros cuyo comportamiento amenace la seguridad del avión, de su tripulación o de otros pasajeros, debido a causas como estar bajo los efectos del alcohol o las drogas, no cumplir con las instrucciones dadas por la tripulación del avión o el personal de tierra referentes a normativas en vigor, mostrar un comportamiento agresivo, violento, alterado o amenazante».

5 Se trata de las reglas que vienen recogidas en los artículos I28r a I289 del Código civil.

6 A estos efectos, resulta importante citar la reciente sentencia de un tribunal de primera instancia en España, el Juzgado mercantil $\mathrm{n}^{\circ} 5$ de Madrid, que en sentencia $\mathrm{n}^{\circ}$ II3/I3 de 30 de septiembre, declara nulas las cláusulas que someten el contrato a la legislación de otro país y a la jurisdicción de los tribunales de ese país por cuanto suponen un desequilibrio importante entre los derechos y obligaciones de las partes que se derivan del contrato cuando el domicilio habitual del consumidor radica en lugar diferente. que la mala intención en la conducta del usuario ha de ser examinada únicamente en relación con el propio contrato y respecto al servicio que se le presta. Queda claro, por tanto, que ha de excluirse cualquier otra mala intención que no esté relacionada con el servicio prestado. Por otra parte, aquellas conductas por parte del usuario que vayan en contra de lo previsto en el contrato ya están cubiertas por otras cláusulas relativas al incumplimiento del contrato, y tanto si se trata de un incumplimiento doloso como negligente. Así pues, acudiendo a la definición inglesa de misconduct, la interpretación que nos cabe deducir de esta cláusula respondería a la necesidad de cubrir la posible responsabilidad de la empresa que ofrece el servicio cuando el usuario realice un uso correcto del mismo pero con la finalidad de causar un daño a terceros (tales como copiar contenidos, piratería, daños a la imagen o la intimidad de otros, etcétera). De este modo se establece el marco legal de utilización del servicio y se permite a la empresa darlo por resuelto si a través del mismo se llevan a cabo conductas perjudiciales para terceros. La conclusión es que con esta cláusula la empresa proveedora del servicio pretende salir al paso de los supuestos de responsabilidad que le impone la ley española en su calidad de prestadora de los servicios de la sociedad de la información ${ }^{7}$.

Sin embargo, tal y como está redactada la cláusula en español, el destinatario de esta prohibición no puede realizar una interpretación clara y directa de la misma si no acude al texto original en inglés; corre, por tanto, el riesgo de quedar indefenso ante una posible suspensión unilateral de los servicios por parte de la empresa proveedora de los mismos. Desde el punto de vista de la interpretación jurídica nos encontramos ante

7 En concreto los artículos I4 a I7 de la Ley 34/2002, de ir de julio, de servicios de la sociedad de la información y de comercio electrónico 
un escollo que podría acarrear la nulidad de la cláusula cuando el destinatario del servicio es un consumidor. En efecto, por aplicación de la legislación española en materia de protección de los consumidores ${ }^{8}$ se consideran abusivas aquellas cláusulas que vinculan el contrato a la voluntad exclusiva del empresario y excluyen la debida reciprocidad en las relaciones. En concreto, se considera falta de reciprocidad el supuesto en el que el empresario puede resolver el contrato discrecionalmente si no se reconoce la misma facultad al consumidor. En todo caso, se trataría de un supuesto de resolución por incumplimiento del usuario que, en caso de discusión, debería ser decidido por los tribunales de Justicia.

Desde el punto de vista de la traducción, en cambio, podemos acudir a la versión en inglés de la misma página web y tomar como texto de partida la cláusula así redactada: «We may suspend or stop providing our Services to you if you do not comply with our terms or policies or if we are investigating suspected misconduct».

El Black's Law Dictionary define misconduct como unlawful or improper behavior, es decir, se trataría de una acción o actividad que podríamos definir como indebida, fraudulenta o irregular. En español, en cambio, el término «mala intención» es mucho más amplio, al tratarse de una muestra de la voluntad o ánimo de la persona, un elemento que es, por tanto, intelectual y que no tiene por qué adoptar la forma de un comportamiento ilegal o impropio. Expresiones correctas en español podrían ser, en este contexto, «conducta irregular», «conducta fraudulenta» o "conducta indebida» $y$ quizá, aunque con más dudas, «mala conducta».

En este contexto, obligaciones y contratos,

8 En especial los artículos 85 y 89 del Real Decreto Legislativo I/2007, de I6 de noviembre, por el que se aprueba el texto refundido de la Ley General para la Defensa de los Consumidores y Usuarios y otras leyes complementarias. catalán y castellano, comparten un mismo ordenamiento jurídico, el regulado en el Código Civil español. En la versión en catalán de la misma página observamos como el término seleccionado se traduce como conducta indeguda y se evita de este modo el uso del término «mala intenció».

Texto en catalán: "Podrem suspendre o deixar de subministrar-li els nostres Serveis en cas d'incompliment de les nostres condicions o de les nostres polítiques, o bé si estem investigant una presumpta conducta indeguda $» .9$

Como hemos indicado antes, si consideramos las versiones en español y en catalán como traducciones del inglés, encontramos que en catalán tenemos una cláusula que, siendo fiel al texto de partida, representa mayor fuente de información para el destinatario final de la misma. En definitiva, entendemos que la prohibición introducida por estas condiciones de uso hace referencia a supuestos en los que se utilice el servicio correctamente pero con la finalidad de causar un daño a terceros. No se trata, por tanto, de juicios morales (a los que podría aludir la expresión «mala intención») sino de calificaciones jurídicas que se pueden deducir de la conducta del usuario en relación con los fines para los que se utiliza el servicio, es decir, «conductes indegudes» o «conductas indebidas».

Hoy por hoy no podemos aportar ejemplos concretos sobre cómo aplican los tribunales este tipo de contenidos jurídicos nuevos que sólo pueden ser considerados como producto de la traducción. Sin embargo, por aplicación de las reglas de interpretación tales como la norma contra proferentem, en caso de duda, el tribunal debería interpretar la norma en contra

9 Podremos suspender o dejar de suministrarle nuestros Servicios en caso de incumplimiento de nuestras condiciones o políticas o bien si estamos investigando una presunta conducta indebida [nuestra traducción]. 
del redactor de la cláusula. En cambio, sí que parece ser constante la jurisprudencia en el sentido de declarar la nulidad de las cláusulas abusivas cuando éstas dejan a una de las partes la libertad de decidir unilateralmente la resolución del contrato. Este tipo de resoluciones judiciales se producen sobre todo en el sector de los contratos de seguros y de viajes y, con mayor restricción, en el sector bancario (véase, a título de ejemplo, la sentencia del Tribunal Supremo, $40 \mathrm{O} / / 2 \mathrm{OIO}$ de I de julio). No tenemos constancia de resoluciones recaídas en el contexto de los contenidos digitales destinados a consumidores por la práctica ausencia de litigiosidad que se detecta en este ámbito.

\section{LAS NORMAS DE PROTECCIÓN DE LOS CONSUMIDORES Y SU IMPACTO EN LA TRADUCCIÓN}

Las condiciones generales de la contratación se caracterizan porque la parte que las suscribe, sin posibilidad de negociación individualizada alguna, suele ser un consumidor final. Los consumidores, en la gran mayoría de legislaciones, gozan de especial protección en materia contractual y, precisamente porque carecen de esta posibilidad de negociación, se obliga a las empresas a presentar su clausulado con «corrección, claridad y sencillez en la redacción» o bien a soportar su declaración de invalidez por parte de los tribunales en caso de impugnación. ${ }^{\text {IO }}$

Las técnicas de traducción y las equivalencias

io La terminología utilizada en los diferentes países varía pero el contenido viene a ser el mismo. Así mientras la Unfair Terms in consumer Contracts Regulations, I999, regulation 7 establece que el vendedor o proveedor del servicio deberá garantizar que todos los términos del contrato están expresados en plain, intelligible language, el RDL I/2007, Ley General para la defensa de los consumidores y usuarios, art. 8o.r.a), utiliza la expresión «corrección, claridad y sencillez en la redacción». utilizadas deberían variar en función del país de residencia del consumidor. Partimos del concepto de consumidor tal y como lo utiliza la legislación de la Unión europea: “'consumer' means a natural person who, in transactions covered by this Directive, is acting for purposes which can be regarded as outside his trade or profession». ${ }^{\text {II }}$ Es por tanto el uso al que se destina el producto o servicio el que marcará la inclusión del contrato dentro de la categoría del Derecho de consumo.

Sin embargo, ni los contratos de licencia ni las condiciones de uso de productos informáticos suelen recoger una mención específica sobre el uso para el cual están destinados. Las empresas redactan de forma genérica los clausulados de modo que pueden ser utilizados indistintamente para la contratación con particulares o profesionales.

En contadas ocasiones este tipo de contratos recogen una restricción de uso en la que se especifica claramente que sólo puede ser destinado a un uso personal y no mercantil. Nos encontramos en este caso con una cláusula de redacción similar a la siguiente:

Subject to your agreement to and continuing compliance with this Agreement and the Terms of Service, we hereby grant to you a nonexclusive, nontransferable, revocable, limited right and license to: (i) install the Software solely for your personal, noncommercial use.

En la cláusula anterior la empresa licenciante establece que el derecho de explotación se limita a un entorno privado en el que la explotación empresarial o profesional podría requerir la licencia o cesión de otros derechos

II Esta definición es la recogida en el artículo 2 de la Directiva 85/577 si bien, con algunas matizaciones, encontramos definiciones similares en la Directiva 90/3I4, 93/133, $94 / 47$, entre otras. 
(posiblemente sujeto a pagos adicionales, para el licenciante) o porque se trata de un producto protegido por una patente (con frecuencia sujeto a regalías en casos de usos profesionales). Los productos que suelen incluir este tipo de limitaciones son juegos, filmaciones, imágenes, música, etc. que, por su propia naturaleza, pueden incluir componentes cubiertos por una o más patentes. En cambio, los sitios o páginas web acostumbran a incluir una cláusula de restricción para uso personal del usuario y con expresa prohibición de utilización para fines comerciales o equivalentes.

Así pues, con excepción de los casos antes citados, la mayoría de contenidos jurídicos digitales no suelen distinguir si están destinados a un uso específico como consumidor o profesional. En el caso de las licencias de uso de programas de ordenador, por ejemplo, el licenciatario viene señalado como usuario final y será la propia naturaleza del programa la que nos pueda indicar si es susceptible de ser explotado comercialmente o puede ser utilizado de forma simultánea en diferentes dispositivos. En efecto, las empresas desarrolladoras de contenidos informáticos suelen incluir algunas limitaciones (p.ej. volumen de dispositivos autorizados para utilizar un mismo programa); sin embargo ello no supone de forma automática que el destino venga limitado para uso personal. En general, en el caso de las licencias el redactado es el mismo tanto si el destino del producto es para consumo personal (una poesía escolar, una lista de la compra, etc.) como profesional (una obra literaria, un contrato, un informe, etc.). Este hecho no tiene implicación práctica en el texto de partida por cuanto el clausulado ha sido redactado en inglés y adaptado al Derecho de los países de Common law. Sin embargo, en traducción, tanto si se aplican las teorías funcionalistas (Nord, 1997), como si se toma como referencia la imposición del derecho aplicable al texto de llegada (Šarcevic, 2000), se deberían adoptar unas técnicas diferentes cuando el destinatario final sea un consumidor, es decir, un receptor de la traducción que se encuentra protegido por unas reglas de interpretación estrictas.

En nuestra opinión, la obligación establecida por la legislación en materia de consumo de "corrección, claridad y sencillez» en la redacción de los contenidos jurídicos dirigidos a consumidores españoles se debe interpretar, en primer lugar, como la obligación de traducir los contenidos al idioma oficial del país. Además, esta obligación debería servir para imponer ciertos criterios de calidad en la traducción tanto en el nivel fraseológico como en el de la terminología utilizada. En efecto, las traducciones deben ser naturales y comprensibles para un hablante nativo del país en cuestión, es decir, depuradas de los giros y frases que no sean conformes con la lengua de llegada o que, por ser poco naturales o comunes, pueden generar confusión. Además, se deben evitar los términos que carezcan de un contenido nocional claro en el ordenamiento jurídico de llegada. Por último, el texto de llegada debe poder ser interpretado a la luz del Derecho de la cultura de llegada, sin necesidad de acudir a otros ordenamientos jurídicos para llegar a comprender los términos inexistentes o que no tengan un contenido delimitado y claro en el Derecho español.

\section{Corrección, claridady sencillez}

- Texto traducido al idioma del consumidor

- Traducción de calidad, es decir que sea naturaly comprensible para un hablante nativo

- Eliminación de términos jurídicos inexistentes en el Derecho español

En definitiva, consideramos que el proveedor de contenidos online incumple con el requisito de información que le impone la ley cuando 
EJEMPLO I

Texto de partida

If you do not accept and comply with these terms, you may not use the software or features. Instead, you should return it to the retailer or other place where you purchased the software license, for a refund or credit.

\section{Texto de llegada}

Si no los acepta, no utilice el software ni sus características. En ese caso, devuélvalo al distribuidor o al lugar donde adquirió la licencia de software, para solicitar un reembolso o crédito. presenta al consumidor un clausulado con términos confusos, inexistentes o que requieran de remisión al ordenamiento jurídico extranjero para una correcta interpretación. En este sentido la stJue de 2I de marzo de 20I3, asunto C-92/Ir, ha establecido que

the system of protection established by Directive $93 / 13$ is based on the idea that the consumer is in a weak position vis-à-vis the seller or supplier as regards both his bargaining power and his level of knowledge, which leads to the consumer agreeing to terms drawn up in advance by the seller or supplier without being able to influence the content of those terms (Case C-453/ro Pereničová and Perenič [20I2] ECR I-oooo, paragraph 27, and Case C-472/Io Invitel [20I2] ECR I-oooo, paragraph 33). In view of that weak position, Directive 93/13 prohibits, first, in Article 3(I), standard terms which, contrary to the requirement of good faith, cause a significant imbalance in the parties' rights and obligations arising under the contract, to the detriment of the consumer.

\section{ANÁLISIS DE LA TRADUCCIÓN DE CONTENIDOS JURÍDICOS EN ENTORNOS DIGITALES}

En este apartado examinamos si los contenidos jurídicos de algunas empresas globales se adaptan al Derecho español. Con este propósito hemos extraído directamente de Internet algunas cláusulas llamadas de miscelánea o condiciones generales, propuestas por empresas multinacionales, que hemos identificado por su notoriedad y porque presentan sus contenidos traducidos a varias lenguas. Para ello hemos seleccionado tanto textos que se presentan como traducciones, como páginas de empresas que ofrecen sus servicios en diferentes versiones lingüísticas. Las observaciones que se realizan son de carácter descriptivo y cualitativo.

Como hemos visto antes, los contenidos jurídicos digitales redactados en español y destinados a consumidores españoles que no toman en cuenta el Derecho español no sólo pueden presentar problemas de traducción, a veces torpemente resueltos, sino también problemas de interpretación por parte de los tribunales de Justicia que pueden incluso redundar en una posible declaración de nulidad.

En el ejemplo i, observamos un uso no natural del término "crédito», que en español peninsular en operaciones comerciales corrientes no tiene el significado que busca el término original. El término más adecuado sería «abono», ya que abarca tanto la emisión de un vale para futuras operaciones como la compensación con otras deudas que el cliente pueda tener con la empresa.

En el ejemplo 2, la traducción introduce un elemento de ambigüedad que no aparece en el original por cuanto «un equipo que pertenezca a alguien más» significa que la propiedad es del antiguo titular además del nuevo. Atendiendo 
EJEMPLO 2

Texto de partida

You may also transfer the software (together with the license) to a computer owned by someone else if...

\section{Texto de llegada}

También puede transmitir el software (junto con la licencia) a un equipo que pertenezca a alguien más si...

EJEMPLO 3

Texto de partida

Because the software is licensed, not sold, the company reserves all rights (such as rights under intellectual property laws) not expressly granted in this agreement.

\section{Texto de llegada}

Debido a que el software es licenciado y no vendido, la empresa se reserva todos los derechos (tales como derechos bajo leyes de propiedad intelectual) no concedidos expresamente en este contrato.

EJEMPLO 4

Texto de partida

Application. This Section 2 applies to any dispute EXCEPT IT DOES NOT INCLUDE A DISPUTE RELATING TO THE ENFORCEMENT OR VALIDITY OF YOUR, PROVIDER'S, OR EITHER OF OUR LICENSORS' INTELLECTUAL PROPERTY RIGHTS. Dispute means any dispute, action, or other controversy between you and PROVIDER concerning the software (including its price) or this agreement, whether in contract, warranty, tort, statute, regulation, ordinance, or any other legal or equitable basis. "Dispute" will be given the broadest possible meaning allowable under law.

\section{Texto de llegada}

Aplicación. Esta Sección 2 se aplica a cualquier disputa con excepción de aquellas disputas relativas al cumplimiento o validez de los derechos de propiedad intelectual otorgados por el proveedor o cualquiera de nuestros licenciantes. Disputa es cualquier disputa, acción o controversia entre usted y el proveedor con relación al software (incluido su precio) o este contrato, ya sea sobre una base contractual, de garantía, de responsabilidad extracontractual, estatutaria, reglamentaria de ordenanza o cualquier otra base legal o equitativa. «Disputa» tendrá el significado más amplio posible permitido por la ley. a que el propósito de esta cláusula es permitir la cesión o transmisión del software a terceros podemos concluir que se trata de una desacertada formulación en español.

En el ejemplo 3, nos vemos obligados a realizar una propuesta de traducción en la que introducimos un equivalente funcional en el TT.

Nuestra propuesta de texto de llegada:

Debido a que el programa es licenciado y no vendido, la empresa se reserva todos los derechos (tales como derechos reconocidos por la legislación de propiedad industrial e intelectual) que no se otorguen expresamente en este contrato.

En el Derecho español el concepto de propiedad intelectual se define como el conjunto de derechos que corresponden a los autores y a otros titulares (artistas, productores, organismos de radiodifusión...) respecto de las obras 
This Agreement shall be governed by and construed under the laws of FRANCE without reference to its conflict of law principles.

These iBigBang Terms are governed by the laws of the European Union without reference to conflict of laws principles.

These Terms shall be governed by and construed in accordance with the laws of the Commonwealth of Massachusetts and the laws of the United States, without giving effect to any principles of conflict of law.

If this contract is with Microsoft Corporation, then claims for breach of this contract will be subject to the laws of the State of Washington, without reference to conflict of laws principles.
Este Acuerdo se regirá por y se interpretará según la legislación de FRANCIA sin referencia a su conflicto de principios legislativos.

Estas Condiciones de iBigBang se rigen por las leyes de la Unión Europea, sin referencia al conflicto de principios legales.

Estas Condiciones se regirán e interpretarán según la normativa legal del estado de Massachusetts y de EE. UU., sin permitir que se produzca ningún tipo de conflicto de leyes.

Si este contrato se celebra con Microsoft Corporation, las reclamaciones por incumplimiento de este contrato estarán sujetas a las leyes del Estado de Washington, sin referencia a conflictos de preceptos de ley. y prestaciones fruto de su creación. No incluye conceptos como patentes, marcas, etcétera, que sí recoge, sin embargo, el concepto en inglés intellectual property. ${ }^{\mathrm{I2}}$ La traducción léxica por lo tanto de este concepto supone una restricción en el ámbito de aplicación del término en la cultura jurídica de llegada. En este caso una traducción informativa, dirigida a consumidores españoles, debería recoger los dos términos que en español peninsular definen totalmente el concepto del texto original. En el ámbito internacional, sin embargo, el término "propiedad intelectual» ha sido acuñado para definir tanto la propiedad industrial como los derechos de autor.

En Derecho español no existe, con el sentido otorgado en el texto de partida del ejemplo 4 ,

I2 «Intellectual property is any product of the human intellect that the law protects from unauthorized use by others», en definición de Blaks' Law Dictionary. la dicotomía legal and equitable basis, que marca una división entre estas dos ramas del Derecho y que establece la diferencia entre normas originadas en el common law o equity law, se trata por tanto de términos culturalmente marcados. En una traducción orientada a la cultura de partida podríamos acudir a alguna de las técnicas de traducción propuestas por los diccionarios tales como perífrasis descriptivas; en este contexto, sin embargo, donde el objetivo es informar al destinatario final sobre los derechos y deberes que se derivan de esta cláusula, el término «equidad» en español podría conducir al destinatario final a confundirlo con el concepto ya existente en español. Una traducción contextual sería la más adecuada, ya que la enumeración termina con un concepto que engloba todos los anteriores como es «cualquier otra base legal». Nuestra propuesta de texto de llegada: 


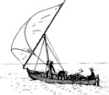

238 a) Aplicación. Las condiciones recogidas en el apartado 2 de este contrato se aplican a toda controversia que pueda surgir con excepción de aquellas controversias relativas al cumplimiento o validez de los derechos de propiedad intelectual e industrial otorgados por el proveedor o cualquiera de nuestros licenciantes. Por «controversia» se entiende cualquier controversia, acción o conflicto entre usted y el proveedor con relación al programa (incluido su precio) o este contrato y con independencia de que su fundamento sea de naturaleza contractual o extracontractual, por incumplimiento de garantía o por cualquier otra base legal. «Controversia» tendrá el significado más amplio posible permitido por la ley.

En general los contratos internacionales suelen incluir una cláusula sobre determinación de la ley aplicable como mecanismo que proporciona seguridad jurídica y previsibilidad en cuanto al alcance de los derechos y obligaciones derivados del contrato. Cuando ambas partes son comerciantes esta cláusula les permite seleccionar el sistema normativo que consideren de su interés. Como ha indicado De Michel (2012: 245), «la precisión de la ley aplicable al contrato internacional mediante una previsión expresa en su clausulado resulta una aportación fundamental, pues permite fijar con certeza el ordenamiento que ha de suministrar los criterios de interpretación de los términos del contrato, el régimen supletorio aplicable a lo no previsto por las partes así como establecer el marco imperativo dentro del que opera la autonomía de los contratantes para acordar los pactos que estimen convenientes en el clausulado del contrato». En defecto de esta cláusula la ley aplicable será la que determinen las normas de conflicto del país cuyos tribunales conozcan del asunto. Son numerosos los contratos internacionales que seleccionan el Derecho inglés como ley aplicable por sus atractivos en materia de desarrollo jurisprudencial y su menor interferencia legislativa en el contrato, lo que permite que sean las partes, a través de un clausulado muy detallado, las que determinen con gran precisión el contenido del contrato. En algunos casos las partes prefieren seleccionar una legislación neutra que no sea ninguna de las leyes nacionales de las partes para conseguir mayor igualdad de negociación. Cuando se trata de un Estado plurilegislativo, como es el caso de Estados Unidos, se aconseja la elección de la ley aplicable de un Estado concreto. En todo caso la selección de una ley aplicable se entiende que supone que la legislación material del país destinado será la que regulará la interpretación del contrato. De modo que no son de aplicación las normas de conflicto de leyes de ese ordenamiento y no opera el reenvío a otros ordenamientos jurídicos que pueda prever dicha legislación. Por esta razón, para evitar cualquier incertidumbre en cuanto a la interpretación de estas cláusulas, se suele incluir una redacción en la que se especifica, de manera expresa, que se excluyen las reglas de Derecho internacional privado del país. En opinión de De Miguel (20I2: 250), esta redacción ampliada es una mera aclaración y simplemente viene a recalcar que «la elección de la ley del contrato debe entenderse referida únicamente a su legislación material sin tener en cuenta la eventual remisión que las normas de conflicto del país elegido realicen a otro ordenamiento». En la UE el derecho aplicable a las obligaciones contractuales está regulado por el Reglamento (CE) 593/2008 de I7 de junio de 2008 sobre la ley aplicable a las obligaciones contractuales (Roma I). Sin embargo, esta libertad de elección de la ley aplicable encuentra especiales limitaciones en materia de consumidores cuando éstos se encuentran en situación de inferioridad con respecto al profesional 
[EJEMPLO 5]

Texto original

This Agreement shall be governed by and construed under the laws of FRANCE without reference to its conflict of law principles.

These iBigBang Terms are governed by the laws of the European Union without reference to conflict of laws principles.

These Terms shall be governed by and construed in accordance with the laws of the Commonwealth of Massachusetts and the laws of the United States, without giving effect to any principles of conflict of law.

If this contract is with Microsoft Corporation, then claims for breach of this contract will be subject to the laws of the State of Washington, without reference to conflict of laws principles.
Texto traducido corregido

Este Acuerdo se regirá e interpretará de conformidad con la legislación de FRANCIA sin que sean de aplicación sus normas sobre conflictos de leyes.

Estas Condiciones de iBigBang se rigen por las leyes de la Unión Europea, con exclusión de sus reglas de Derecho internacional privado.

Estas Condiciones se regirán e interpretarán según las leyes del estado de Massachusetts y de EE. UU., con exclusión de sus reglas Derecho internacional privado.

Si este contrato se celebra con Microsoft Corporation, las reclamaciones por incumplimiento de este contrato estarán sujetas a las leyes del Estado de Washington, sin que sean de aplicación sus normas sobre conflictos de leyes. o comerciante. ${ }^{13} \mathrm{E}$ lérmino «conflicto de leyes» se refiere a los principios sobre determinación del Derecho aplicable y es un sinónimo de las normas de Derecho internacional privado. Se refiere al cuerpo de principios jurídicos que se ocupa de reconciliar las diferencias en cuanto al Derecho aplicable y de determinar el Derecho que regirá en una situación determinada. El reglamento Roma I excluye el reenvío y, por lo tanto, la referencia a una determinada ley debe interpretarse como la sumisión directa al derecho material de un país determinado. De este modo se evita que, por aplicación de las normas sobre conflicto de leyes del país en cuestión, el tribunal acabe aplicando el Derecho de otra jurisdicción.

I3 Véase a este respecto la ya citada sentencia Ryanair.
Los ejemplos que mostramos en el cuadro anterior reflejan que el concepto de conflict of laws no ha sido tratado como un término especializado; solamente así se puede entender que la formulación final en español se vea desprovista de su contenido nocional y resulte tan alejada de la finalidad perseguida.

\section{CONCLUSIONES}

Uno de los objetivos de este trabajo era analizar el impacto del Derecho aplicable en el resultado de la traducción. Especialmente en el ámbito del Derecho tecnológico y de los contenidos jurídicos de las páginas web resulta importante tomar en consideración si las traducciones o contenidos jurídicos se adaptan al Derecho 
español cuando el destinatario del texto o usuario final es el consumidor. En efecto, la legislación europea en materia de consumo ha establecido un sistema de protección basado en la idea de que el consumidor se encuentra en una situación de inferioridad con respecto al profesional. Esta situación de inferioridad, que deja en evidencia la total ausencia de capacidad de negociación por parte del consumidor, debe ser contrarrestada mediante la obligación que se impone al profesional de llevar a cabo un esfuerzo especial de información y claridad en las condiciones de contratación con las que opera. Por ello los profesionales suelen presentar los contenidos digitales en la lengua del país al que van destinados sus productos o servicios. Normalmente las empresas presentan sus contenidos digitales traducidos o redactados «originalmente» en español. Sin embargo, los ejemplos recogidos en este trabajo muestran que la influencia del Derecho extranjero puede acabar comprometiendo el nivel de información que se ofrece al destinatario final de los contenidos. Cuando el consumidor se ve obligado a adherirse a un clausulado en el que no solo se aprecia la influencia de una legislación extranjera sino que, sin acudir a esta resulta imposible conocer el alcance exacto de sus obligaciones contractuales y de sus derechos, la obligación de información no se cumple. Por otra parte, el hecho de que estos contenidos jurídicos estén volcados en Internet, convertida hoy en día en una fuente impagable de textos comparables en la que los motores de búsqueda drenan sus resultados, y otras herramientas web, tiene un evidente impacto en la acuñación de equivalentes que generan nuevos elementos de inseguridad jurídica cuando deben ser analizados a la luz de un derecho nacional concreto. Recuperar la vieja dicotomía de la traducción fiel al original pero también como eficaz fuente de información para el destinatario final nos permite dar prioridad a unas técnicas de traducción que tomen en consideración el ordenamiento jurídico de llegada. Hoy en día, más que nunca, podemos concluir que el esfuerzo de interpretación ex ante que realiza el traductor repercute sin duda en una mayor seguridad jurídica para la interpretación jurídica del texto de llegada y, por lo tanto, se convierte en la mejor garantía de supervivencia para las cláusulas que componen las condiciones generales de la contratación.

RECIBIDO EN MAYO DE $20 I 4$ ACEPTADO EN OCTUBRE DE 2014 VERSIÓN FINAL DE NOVIEMBRE DE $20 I 4$

\section{REFERENCIAS}

Bestué, C. (2009). Las traducciones con efectos juridicos. Estudio de la traducción instrumental de las licencias de programas de ordenador, Departamento de Traducción e Intepretación, Universitat Autònoma de Barcelona, Tesis doctoral.

Bestué, C. (2013). Los contratos traducidos. La traducción de los contratos de licencia de uso en programas de ordenador, Derecho y TIC's, Valencia: Tirant lo Blanch.

Borja, A. (2005). «Organización del conocimiento para la traducción jurídica», en I. García-Izquierdo (ed.). El género textual y la traducción. Reflexiones teóricas y aplicaciones pedagógicas, Berna: Peter Lang.

De Groot, R., van Laer,C. (2008). «The Quality of Legal Dictionaries: An Assessment» (2I de Octubre de 2008). Disponible en http://ssrn.com/ abstract=I287603 or http://dx.doi.org/Io.2139/ ssrn.1287603De Miguel, P.A. (2012). «Cláusulas de elección del Derecho aplicable». En Sixto A. Sánchez Lorenzo (coord.). Cláusulas en los contratos internacionales. Redacción y análisis, Barcelona: Atelier libros jurídicos.

Didier, S. (1990). Langues et langages du droit Montreal: Wilson \& Lafleur. 
Díez-Picazo, L. (2007). Fundamentos del Derecho Civil Patrimonial I. Introducción. Teoría del Contrato, sexta edición, Cízur Menor (Navarra): Thomson, Civitas.

Galdia, M. (2003). «Comparative law and legal translation». The European Legal Forum I: I - 4. Gémar, Jean Claude. 1998. "Les enjeux de la traduction juridique. Principes et nuances”. Traduction de textes juridiques : problèmes et méthodes, Equivalences 98, Séminaire ASTTI. Disponible en: http:// www.tradulex.com/Berni998/Gemar.pdf

Hurtado, A. (200I). Traducción y Traductología, Granada: Cátedra.

Mayoral, R. (I997-98). «La traducción especializada como operación de documentación». Sendebar, 8/9, pp. I37-I54.

Mayoral, R. (1999). «Las fidelidades del traductor jurado: batalla indecisa». En Manuel Feria ( ed.). Traducir para la justicia. Granada: Comares, pp. 17-58.

Mayoral, R. (2004). «Lenguajes de especialidad y traducción especializada. La traducción Jurídica». En Consuelo Gonzalo y Valentín García-Yegra (eds.), Manual de documentación y terminología para la traducción especializada, Madrid: Arco/ Libros, pp. 49-7I.

Melero,M., Badia, T., y Moreno, A. (20I2). La lengua española en la era digital. Serie de Libros Blancos Metanet. Heildeberg: Springer. Disponible en: http://www. meta-net.eu/whitepapers/e-book/spanish.pdf

Monjean-Decaudin, S. (2012). La traduction du droit dans la procédure judiciaire. Contribution à l'étude de la linguistique juridique, París: Dalloz.

Monzó, E. (2002). La professió del traductor jurídic $i$ jurat. Descripció sociològica de la professió $i$ anàlisi discursiva del transgènere, Departamento de Traducción y Comunicación, Universitat Jaume I, tesis doctoral.

Monzó, E. (2005). «Being ACTIVE in Legal Translation and Interpreting: Researching and Acting on the Spanish Field», Meta, 50/4.

Nord, C. (1997). Translating as a purposeful activity. Functionalist approaches explained, Manchester: St. Jerome Publishing.
Pym, A. (2008). «On Toury's laws of how translators translate». En Anthony Pym et al. (ed.), Beyond Descriptive Translation Studies, Amsterdam: Benjamins, pp. $3 \mathrm{II}-328$.

Šarcevic, S. (1985). «Translation of culture-bound terms in laws». Multilingua 4/3, pp.I27-I33.

Šarcevic, S. (I988). «Terminological Incongruency in Legal Dictionaries for Translation». Euralex Proceedings. Disponible en: http://www. euralex.org/elx_proceedings/Euralexi988/057_ Susan\%2oSarcevic\%20\%28Rijeka\%29\%20-\%20 Terminological\%2oIncongruency\%2 oin\% 20 Legal\%20Dictionaries\%2ofor\%2o Translation. pdf.

Šarcevic, S. (1997). New apporach to Legal Translation. The Hague, London, Boston: Kluwer Law International.

Šarcevic, S. (2000). «Legal Translation and Translation Theory: a Received-oriented approach». En: ASTTi/ETI. (ed.), Berna, pp. 329-347. Disponible en: http://www.tradulex.org/Actes200o/šarcevic. pdf.

Shreve, G.M. (2006). "Corpus enhancement and computer-assisted localization and translation». En Keiran J. Dunne (ed.) Perspectives on Localization. Amsterdam/Philadelphia: John Benjamins Publishing Company, pp. 309-33I.

Toury, G. (1995). «The Nature and Role of Norms in Translation». En Descriptive Translatin Studies and Beyond, Amsterdam-Philadelphia: John Benjamins, pp. 53-69.

Vargas Sierra, C. (20I2). «La tecnología de corpus en el contexto profesional y académico de la traducción y la terminología: panorama actual, recursos y perspectivas». En Candel-Mora, M.A. y Ortega-Arjonilla, E. (eds.), Tecnologia, Traducción y Cultura, Valencia: Editorial Tirant lo Blanc, pp. 67- 99. Disponible en: http://goo. g1/Bowo3B

Weston, M. (199I). An English reader's guide to the French legal system, Nueva York y Oxford: Berg.

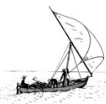

